\title{
e-interview
}

\section{Simon Wessely}

Simon Wessely is Professor of Epidemiological and Liaison Psychiatry at the Institute of Psychiatry, London. He trained in Cambridge, Oxford, Newcastle and the Maudsley Hospital. His special interests include psychological treatments and psychiatry in the military.

If you were not a psychiatrist, what would you do?

The opportunity to open the batting for England has now passed, so I would like to be a modern historian.

What has been the greatest impact of your profession on you personally? The intellectual stimulation and curiosity of my colleagues, and occasionally myself.

Do you feel stigmatised by your profession?

No, I am proud of it.

What are your interests outside of work?

History, skiing, journalism, arguing.

Who was your most influential trainer, and why?

Michael Shepherd - for introducing me to epidemiology; Maria Ron, for beginning my interest in chronic fatigue.

What job gave you the most useful training experience?

Queen Square liaison psychiatry - all human life was there, and that was just the neurologists. The patients were even more interesting, and after years in Camberwell it was a pleasure to work in a place near some good cafés to indulge my principal outside interest - arguing.

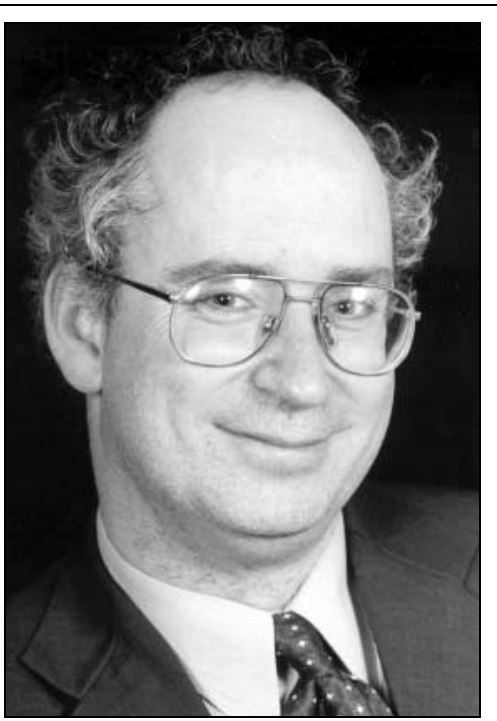

What research publication has had the greatest influence on your work? Deviant Children Grown Up by Lee Robins.

What part of your work gives you the most satisfaction?

Having coffee with my colleagues.

\section{What do you least enjoy?}

Administration and bureaucracy which makes me find solutions for things which aren't problems.

What is the most promising opportunity facing the profession?

New technologies and electronic records.

\section{What is the greatest threat?}

The Data Protection Act - not the Act itself, but the risk-aversive way in which it is interpreted by people who haven't read it.
What single change would substantially improve quality of care? Electronic records.

What conflict of interest do you encounter most often?

Work versus family.

Do you think psychiatry is brainless or mindless?

Anyone who is either is no psychiatrist.

How would you entice more medical students into the profession? With charismatic general hospital psychiatrists

What is the most important advice you could offer to a new trainee? Read more. Ski more. Take the time to bond with your fellow trainees - you never know when you will need their support.

What are the main ethical problems that psychiatrists will face in the future?

Dangerous personality disorder legislation.

How would you improve clinical psychiatric training? Use the general hospital more.

What is the future for psychotherapy in psychiatry training and practice? Good, provided it is broad based and fully representative of all the psychotherapies, including cognitive and behavioural.

What single area of psychiatric research should be given priority? Large simple randomised controlled trials.

What single area of psychiatric practice is most in need of development? Talking treatment skills, especially cognitive-behavioural therapy.

Dominic Fannon 